\title{
Investigating the Effect of Wiki-Based Corrective Feedback on Accuracy of L2 Learners' Written Production
}

\author{
Shamsurahman Adel ${ }^{1}$, Nik Aloesnita Bt Nik Mohm Alwi ${ }^{2}$ \\ ${ }^{1}$ Department of English Language, Nangarhar University (NU), Nangarhar, Afghanistan \\ ${ }^{2}$ Department for Modern Languages and Human Sciences, University Malaysia Pahang (UMP), Pahang, Malaysia
}

Email address:

shams_55000@yahoo.com (S. Adel), aloesnita@ump.edu.my (N. A. Bt N. M. Alwi)

\section{To cite this article:}

Shamsurahman Adel, Nik Aloesnita Bt Nik Mohm Alwi. Investigating the Effect of Wiki-Based Corrective Feedback on Accuracy of L2 Learners' Written Production. International Journal of Applied Linguistics and Translation. Vol. 5, No. 3, 2019, pp. 48-54. doi: $10.11648 /$ j.ijalt.20190503.13

Received: June 26, 2019; Accepted: September 3, 2019; Published: September 19, 2019

\begin{abstract}
Providing feedback to and correcting errors of learners' language performance is important in both first (L1) and second language (L2) teaching and learning process. A number of studies have examined the effectiveness of different types of corrective-feedback (CF) on L2 learners' writing and results showed positive effects [1-3]. However, little has examined the effects of CF on L2 writing via wiki [4-5]. Therefore, the current study aims to provide further insights into the effects of implicit CF on L2 learners' writing through wiki. Nineteen $(n=19)$ undergraduate L2 learners doing English at University Malaysia Pahang were enrolled in the study. During the pretest session, the learners were required to write an essay on Communication Skills at Workplace for approximately one hour. Next, implicit CF was provided to the essays, and a week later during the posttest session, the learners revised their essays based on the feedback given. Results indicated that wikibased implicit CF helped L2 learners to improve the accuracy of their written productions as evident in total number of error per T-unit (E/T-unit) and total number of error per clauses $(\mathrm{E} / \mathrm{C})$. The findings of the study would have great impact and would help the L2 professors and students teaching and learning the L2.
\end{abstract}

Keywords: Implicit Corrective Feedback (ICF), Wiki, Accuracy

\section{Background}

Corrective feedback (CF) is information given to learners regarding errors they have made during their study and is important in both first (L1) and second (L2) language learning [6]. CF serves as a hint to the learners that their use of the target language is incorrect and is significant in writing classes [7-8]. It is debated whether teacher should treat learners' errors as part of the learning process [9-12]. One of the arguments is put forth by Truscott who claimed that error correction is ineffective in language classes [12-15]. Error correction could have negative effects on learners' ability to produce accurate language, and he added "we should be confident whether if the correction has any actual benefits that will be very small" [14, p. 256].

However, a number of studies provide evidence in support of CF, i.e., [9-11, 17-18, 20-23]. For instance, two groups of learners were examined to see the influence of grammatical error correction on learners' work [10]. It was found that the group received $\mathrm{CF}$ gained more accurate language over the control group. Findings of the study by Chandler correlated to the findings of the study by [10]. Total number of errors/total number of 100 words ratio is used to measure the accuracy [16]. Analysis of covariance was used to investigate differences in the results of the experimental and control groups. Results found no significant difference on the first assignment between the two groups as evident in $(t=2.05$, $p>0.05)$. Meanwhile, her study did not show significant difference of the mean error for 100 words of control group when the data was analyzed from first and fifth assignment as indicated by $(t=-0.90, p>0.05)$. On the other hand, there was a significant difference in the grammatical and lexical errors per 100 words in which the learners in the experimental group made an average of 7.8 errors in their first assignment and reduced to 5.1 errors per 100 words in the fifth assignment $t=4.05, p<0.05$. Recently, Truscott's claims was tested by [17]. Contrary to Truscott claim, the study found 
that learners who were provided with CF significantly produced more accurate $(p<0.05)$ language over control group ( $p>0.05)$ [17]. Similarly, it is claimed that CF encouraged learners to produce writing with minimal errors and maximum accuracy and clarity [18].

On the other hand, it is claimed that CF not only helped learners improved the accuracy of their writings in short term; it also provided them with a long term benefit [19]. The study stated if correction is to be targeted on specific types of errors; it would have positive effects on linguistic accuracy of learner language productions. In line with this argument, a study affirmed that by targeting specific language features for error correction, it not only assisted learners to improve linguistic accuracy of their written productions in the long term, it also pushed them towards effective communication [22]. In terms of linguistic accuracy, the study by Evans asserted similar findings to [9-11]. Thirty $(n=30)$ undergraduate ESL learners were assigned into two a control and treatment groups. Error-free clause ratio was analyzed to measure the accuracy of learners' written productions. Results showed that written CF helped learners in the treatment group to improve the accuracy of their written productions over control group.

As indicated in literature above, researchers have different beliefs about the effectiveness of $\mathrm{CF}$ based on their research findings. Also, there were number of studies investigated the possible effects of different types of CF on L2 learner written and oral productions. As such, more research is needed to provide further insights particularly into the area of different types of CF on written production.

\subsection{Types of Corrective-feedback}

Corrective feedback (CF) can be provided in different forms, i.e., explicit correction, recasts, prompt, elicitation, clarification, repetition of error, and meta-linguistic feedback $[3,25-27]$. It is explained that the various responses learners may receive to correct their erroneous [7]. For example, when a language learner says, 'He write his homework every day', CF can be explicit, for instance, 'no, you should say writes, not write' or implicit 'yes he writes his homework every day', and may or may not include metalinguistic information, i.e., 'Don't forget to make the verb agree with the subject. In general $\mathrm{CF}$ is classified into implicit and explicit CF [28]. Explicit corrective feedback (ECF) provides learners with target modals to the errors they made during their work; whereas, implicit corrective feedback (ICF) does not provide the target model. ICF is used in a way that simply highlights the errors learners made, allowing them to correct the errors themselves [28-29]. Literature has argued that both explicit and implicit CF assist L2 learners to improve the linguistic accuracy of their written productions $[20,30]$, and different types of CF have different effects on ESL/EFL learner writing [1].

A number of studies reported that explicit corrective feedback (ECF) is more effective in improving the linguistic accuracy of a learner written productions [2, 20, 30-32]. For instance, study a found that providing ECF had positive effects on L2 learner written productions [32]. The findings of the studies by Bitchener and Falhasiri correlated to the findings by Nazari. For example, it was investigated that different types of written CF can impact the linguistic accuracy of learners' written production [20]. The data was collected in three stages as a pretest, immediate posttest, and delayed posttest, and the learners were asked to describe different pictures in writing. Different types of CF were provided to measure the usage of definite and indefinite articles. Results found that all the treatment groups outperformed the control group in the immediate posttest. However, during the delayed posttest, only the learners in meta-linguistic explanation and meta-linguistic explanation with oral instruction gained accuracy during the ten weeks period than implicit and control groups.

In contrary, a number of studies vigorously defend the effectiveness of implicit corrective feedback (ICF) and provide evidence to support their claims. They believe that ICF assist L2 learners to improve the linguistic accuracy of their language productions [1, 34-37]. For instance, it was found that ICF significantly affected the linguistic accuracy of learners' written production over explicit CF [1]. Sixty $(N=60)$ EFL learners were enrolled in explicit corrective feedback (ECF), implicit corrective feedback (ICF), and no feedback groups. The data collected from pre and posttests showed significant difference between the groups, and suggested that learners participated in ICF outperformed both over the explicit and control groups. The findings of the studies by Campillo, and Zhao are similar to the findings by Ahmadi. Moreover, a study claimed that ICF was more effective than explicit for two reasons as 1) it helped learners improve the quality of their written text with understanding the significance or value of $\mathrm{CF}$, and 2) it also had positive effects on long-term writing proficiency of L2 learner language production [38].

It still remains a question whether implicit or explicit $\mathrm{CF}$ is more effective in improving learner language productions. Implicitness or explicitness can impact learner perception which influences its effectiveness [23, 25]. A study suggested that two important factors should be considered in implementing $\mathrm{CF}$, i.e., to know whether the learners should receive implicit or explicit $\mathrm{CF}$ or a combined form of the feedback. It was found that mixed CF (both implicit and explicit) was more effective in L2 classes [39]. On the other hand, a study claimed that providing different types of $\mathrm{CF}$ with no discussion and clarification might not be effective [11]. It collected four different under timed condition texts from ten participants. Then, each text was revised by the researchers, and they provided learners with feedback. After each revision, learners were required to participate in interviews and talk about the written CF provided to them. Results indicated that the learners were satisfied with the course outcomes while they asked for more clarification. The studies reviewed above provided insights into positive effects of CF on learner writing. However, the feedback on learner written production was given in a traditional paper and pen form. It would be interesting to find out whether there are 
positive effects of $\mathrm{CF}$ on learner writing when feedback is provided via wiki (a $2.0 \mathrm{web}$ ). The following section further discusses this.

\subsection{Wiki: A 2.0 Web}

Wiki is a freely expandable collection of interlinked web pages, a hypertext system for storing and modifying information, and a database where each page can easily be edited by any users [40]. Wiki is a set of linked web pages that is shaped through an incremental development by a group of users [41]. It is an easy-to-use platform for collaborative work on texts and hypertexts [42], and it is open accessed [43]. In addition, it is believed that the ease of procedure and communication made wiki a useful tool for group collaborative authoring, and it can be used to gain information from their teacher and other learners [44].

Researchers acknowledge that the use of wiki can have positive effects on learning process, and can be used as an effective collaborative tool for writing in language classes [5, 45-48]. For instance, it is found that learners collaborated and participated equally via wiki [5]. The study also showed that most of the learners, who used wiki in their classes, were able to write, rewrite and edit their group works anytime from anywhere. Moreover, the discussion that took place about writing, editing, feedback, and other interactions helped them in improving their written assignments. The Findings of the study by Zailin, Nik and Ainol were supported by [49]. They indicated that wiki offered collaborative, flexible, rich and empowered learning environments, and the learners were highly satisfied when they used wiki.

In addition to collaboration, some researchers also highlighted wiki as one of the best tools in teaching and assessing the learners' performance in language classes [4-5, 50-51]. For example, it was pointed out that wiki did not only assist learners to improve their essay writing performance, it also improved their critical thinking skills [51]. Findings of the study by Barry correlated with the findings of the study by [51]. The study assessed learners watching their presentations via wiki and revealed that watching the videos of learners' group presentation was an effective method of feedback and could improve group and individual performance.

Furthermore, it was asserted that wiki could also be used as an effective tool for teaching writing because revisions and feedback can easily be analyzed and addressed using this editable web-based tool [4]. The researcher reported that during 10 weeks of study a total of 1553 of feedback were given via wiki. The revision made by the learners to their report writing has improved the text quality of their writing, and this was well acknowledged by the learners. The findings of the study by Zailin are recently echoed by the study [52]. It investigated that wiki could assist learners to improve their writing by receiving comments from their peers and teachers. The study examined integrating assessment for learning as a practical pedagogy to improve the quality of their wiki-based project. Seventy-six $(N=76)$ participants were enrolled at a teacher training institute in Hong Kong. Results indicated a total of 451 comments were provided on wiki which showed the eagerness of learners condense their comments to peers. Participants of the study pointed out that teachers and peers comments helped them improve the quality of their wiki project.

The above descriptions on the effectiveness of wiki may well relate to the teaching and learning approaches the instructors or researchers have employed. Nevertheless, most of the studies sought to measure the impact of $\mathrm{CF}$ on linguistic accuracy of learner written or oral productions in a traditional way i.e., paper and pen form. Also, as reviewed earlier, providing $\mathrm{CF}$ is one of the beneficial assistances instructors may offer the learners with, and it would be interesting to find out whether there are positive effects of $\mathrm{CF}$ on accuracy of learner written productions when feedback is provided via a 2.0 web. As such, the current study aims to fill the gap.

\section{Research Materials and Methods}

The current study was conducted at one of the technical universities in Malaysia. It was designed to investigate the extent to which wiki-based implicit CF can help L2 learners improve the accuracy of their written productions as evident in their writing via wiki. Nineteen $(n=19)$ undergraduate learners doing English for Professional Communication course participated in the study. Their age ranged between 18-22 years and their L1 were either Malay, Chinese or Tamil. Their English proficiency was at a low level as evident from their Malaysian University English Test $\left(\mathrm{MUET}^{1}\right)$ results in which majority of the learners achieved band two and a few achieved band three in the exam. Throughout the semester and when the study took place, the teaching and learning sessions were conducted in language labs.

As such, learners were able to use computers with internet connection for classroom activities including assessing and writing on wiki. One research question was framed with the aim to investigate the following:

1: How does wiki-based implicit CF affect the accuracy of L2 learner written production?

\subsection{Design}

The data was collected in two stages as pretest and posttests. During pretest, the learners were required to write an essay about communication at workplace for one hour. The topic was familiar to them as the course content was designed in such a way that it relates to communication at workplace. Next, the researcher provided implicit $\mathrm{CF}$ via wiki to the learners' essays. After a week interval, posttest was carried out whereby the learners, individually, were given one hour to revise their essays based on the implicit

\footnotetext{
1 Full description of MUET aggregated scores can be downloaded from http://www.mpm.edu.my/web/guest/regulations-test-specifications-test-formatand-sample-questions
} 
corrective feedback (ICF) provided to them.

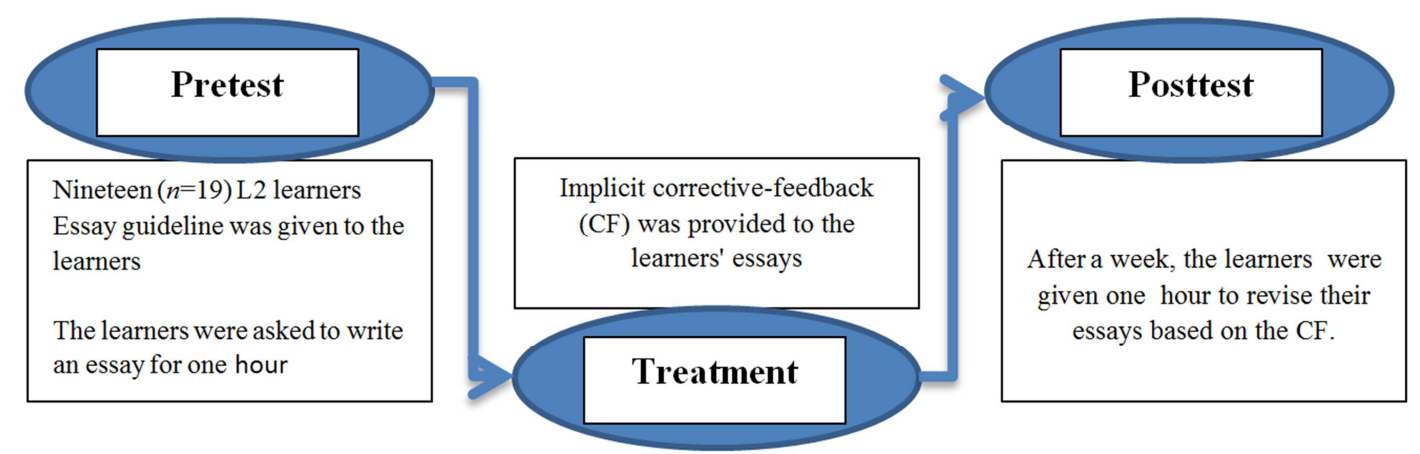

Figure 1. Data collection process.

\subsection{Data Analysis}

Learner written essays on communication at workplace from pretest and posttest were analyzed to investigate if wikibased implicit CF could help learners improved the accuracy of their written production. Total number of errors per T-units $(E / T)$ and total numbers of errors per clauses $(E / C)$ were analyzed to measure accuracy of learner written productions. The data was analyzed using Microsoft Excel and SPSS. Paired-samples t-test was administered to answer the question. It finds out about $\mathrm{p}$ value that shows significant difference between the pretest and posttest of the study. Paired-samples t-test provides the difference in two steps. First, if the $p$ value is $p>0.05$, it means there is no significant difference between the pretest and posttest. However, if the $\mathrm{p}$ value is $p<0.05$, it means there is a significant difference between the two tests results. To assure the reliability of wiki-based implicit corrective (ICF) and data analysis process, 25 percent of the whole data was coded. Errors per T-unit length was analyzed to observe the reliability of the $\mathrm{CF}$ as at least 10 percent of the data should be coded to establish confidence in raters' reliability [55]. The inter-rater reliability test was assessed through MedClac, and it showed strong agreement between the raters as $k=0.86$.

Table 1. Measure of accuracy of learner written productions.

\begin{tabular}{ll}
\hline Accuracy & $\mathrm{E} / \mathrm{T}$ \\
$\mathrm{E}=$ total number of errors, $\mathrm{T}=$ total number of $\mathrm{T}$-unit, $\mathrm{C}=$ total number of
\end{tabular}
clauses.

\section{Results}

As indicated earlier, paired t-test was administered on two measures for accuracy in order to answer the research question. Results show that learners yielded higher accuracy when they receive implicit $\mathrm{CF}$ via wiki in the posttest as measured by $\mathrm{E} / \mathrm{T}$ and $\mathrm{E} / \mathrm{C}$.

With respect to accuracy, results by means of pairedsamples $t$-test showed that implicit $\mathrm{CF}$ via wiki affected the accuracy of L2 learners' written production as E/T and E/C were analyzed. Results indicated that after providing implicit $\mathrm{CF}$ via wiki, learners significantly produced more accurate language in posttest as evident in $\mathrm{E} / \mathrm{T} t(19)=17.367, p=<0.05$ and $\mathrm{E} / \mathrm{C} t(19)=11.622, p=<0.05$.

Table 2. Effects of wiki-based implicit CF on accuracy of learner written productions.

\begin{tabular}{|c|c|c|c|c|c|c|c|c|}
\hline & \multicolumn{5}{|c|}{ Paired Differences } & \multirow{3}{*}{$t$} & \multirow{3}{*}{$D f$} & \multirow{3}{*}{$\begin{array}{l}\text { Sig. (2- } \\
\text { tailed) }\end{array}$} \\
\hline & \multirow{2}{*}{ Mean } & \multirow{2}{*}{$\begin{array}{l}\text { Std. } \\
\text { Deviation }\end{array}$} & \multirow{2}{*}{$\begin{array}{l}\text { Std. Error } \\
\text { Mean }\end{array}$} & \multicolumn{2}{|c|}{ 95\% Confidence Interval of the Difference } & & & \\
\hline & & & & Lower & Upper & & & \\
\hline Pretest E/T Posttest E/T & 1.64 & .41 & .09 & 1.44 & 1.84 & 17.36 & 18 & .00 \\
\hline Pretest E/C Posttest E/C & 1.06 & .40 & .09 & .87 & 1.26 & 11.62 & 18 & .00 \\
\hline
\end{tabular}

Figure 2 indicates that the mean score of $\mathrm{E} / \mathrm{T}$ ratio of learners participated in the study decreased from $M=1.86$ $(S D=0.38)$ in pretest to $M=0.22(S D=0.20)$ in posttest.

Likewise, the mean score of $\mathrm{E} / \mathrm{C}$ ratio decreased from $M=$ $1.19(S D=0.41)$ in pretest to $M=0.12(S D=0.10)$ in posttest that show a significant impact of wiki-based implicit $\mathrm{CF}$ via wiki on accuracy of L2 learner written productions.

\section{Discussion}

The aim of the current study was to investigate the effects of implicit CF on accuracy of learner written productions in a wiki platform. For the purpose of the study, data in form of written essays on wiki by 19 L2 learners were collected and analyzed. Paired-samples t-test was administered as the statistical analysis on two measures for accuracy. Overall, results of the analysis showed significant effects of wikibased implicit $\mathrm{CF}$ on accuracy of learner written productions.

Table 3. Effects of wiki-based implicit CF on accuracy of learner written productions.

\begin{tabular}{llll}
\hline Measures & Dependent Variable & Independent Variable & Results \\
\hline \multirow{2}{*}{ Accuracy } & $1 . \mathrm{E} / \mathrm{T}$ & ICF via Wiki & $p<0.05$ \\
& $2 . \mathrm{E} / \mathrm{C}$ & ICF via Wiki & $p<0.05$ \\
\hline
\end{tabular}

Note: $\mathrm{E} / \mathrm{T}=$ total number of errors per total number of $\mathrm{t}$-units, $\mathrm{E} / \mathrm{C}=$ total number of errors per total number of clauses, ICF $=$ implicit corrective feedback 
Total number of errors per total number of T-units $(\mathrm{E} / \mathrm{T})$ and total number of errors per total number of clauses $(\mathrm{E} / \mathrm{C})$ ratios were measured to analyze accuracy of learner written productions [54]. As indicated in table 3, wiki-based implicit $\mathrm{CF}$ pushed learners to produce more accurate language. This is reflected in a decrease in number of errors. The findings of the current study provide full support to Ferris [9-10] findings, i.e., error correction helped learners improve the linguistic accuracy of their language productions. Likewise to Ferris a number of recent studies found similar findings [1, $17,20,23-24,36]$, i.e., CF helped learners to improve the linguistic accuracy of their written productions.

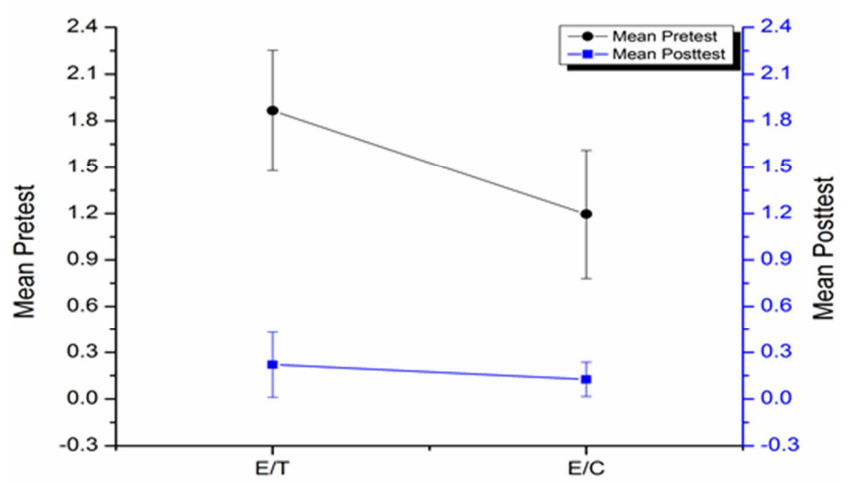

Figure 2. Effect of wiki-based implicit CF on accuracy of learner written productions.

Additionally, it is stated that implicit CF might be more vigorous (i.e. longer lasting) and effective [38, 55]. Most of the previous studies stated earlier investigated the effects of $\mathrm{CF}$ on linguistic accuracy of L2 learner written productions in a traditional way, i.e., paper and pen form [1, 20, 23-24]. However, this study provided CF via a web 2.0 technology as it is actively used by the educators during the second language teaching and learning activities. For example, the importance of providing feedback on learner writing via wiki has been highlighted [4].

Over all, it indicates that implicit CF made the learners capable of paying greater amount of attention to accuracy of their written productions $[1,9,17,38]$. In addition, wiki might also help learners to increase accuracy of their written productions as they were able to revise and edit their essays on the same page that might heighten their attention to forms [5]. Table 4 illustrates the effects of wiki-based implicit CF on accuracy of learner written productions.

Table 4. Effects of wiki-based implicit corrective feedback on accuracy of learner written production.

\begin{tabular}{llll}
\hline Measures & Sub measures & Current study & Previous studies \\
\hline \multirow{2}{*}{ Accuracy } & $1 . \mathrm{E} / \mathrm{T}$ & $p<0.05$ & $p<0.05$ \\
& 2. E/C & $p<0.05$ & $p<0.05$ \\
\hline
\end{tabular}

Note: $\mathrm{E} / \mathrm{T}=$ total number of errors per total number of $\mathrm{t}$-units, $\mathrm{E} / \mathrm{C}=$ total number of errors per total number of clauses.

\section{Conclusion}

The aim of the study was to find out the effect of wiki- based implicit CF on L2 learners' written productions. A pre and posttest design was used to collect data from learners. Overall findings of the study illustrated that wiki-based implicit CF significantly affected the accuracy, fluency and GI of the lexical complexity of learners' written productions. The findings of the study support the findings of the earlier empirical studies that CF helped learners improved their language productions particularly accuracy and fluency. Because only one measure of lexical complexity shows the significant effect, more studies should be carried out to provide more insights into this matter.

The study conducted at University Malaysia Pahang (UMP) and used the learners who used Wiki technology in their English language classes; therefore, the findings maybe applicable to those who are in similar learning context. It focuses only on wiki-based implicit $\mathrm{CF}$ and its effectiveness in learners writing; to determine the extent to which it may help them improve their writing. In addition, the learners in the current study were at a lower proficiency level. Therefore, further research may use advanced L2 learners as language proficiency can affect language development while there is need for further research in this area [56].

\section{Acknowledgements}

The research process of this study was sponsored by Ministry of Higher Education of Afghanistan (MoHE) in collaboration with University Malaysia Pahang (UMP). The authors would like to thank the technical staff of Center for Modern Languages and Human Sciences at UMP who provided their valuable help and assistance during the study.

\section{References}

[1] Ahmadi, D., Maftoon, P. \& Mehrdad, A. G. (2012). Investigating the Effects of Two Types of Feedback on EFL Students' Writing. Social and behavioral sciences, 46, 25902595 .

[2] Kamberi, L. 2013. The significance of teacher feedback in EFL writing for tertiary level foreign language learners. Social and behavioral science. 70, 1686-1690.

[3] Lyster, R. \& Saito, K. (2010). Oral feedback in classroom. Studies in second language acquisition, 32, 265-302.

[4] Zailin, S. Y. (2010). Evaluating the impact of feedback given via wikis on ESL students' reports. Unpublished doctoral dissertation, International Islamic University Malaysia.

[5] Zailin, S. Y, Nik, A, \& Ainol, H. (2012). Investigating students' perception of using wikis in Academic writing. 3L: The southeast Asian Journal of English Language Studies, 18 (3), 91-102.

[6] Sheen, Y. 2007. The effects of corrective feedback, language aptitude, and learner attitudes on the acquisition of English articles. In: A. Mackey, ed., Conversational interaction in second language acquisition: a collection of empirical studies. (301-322). Oxford: Oxford University Press. 
[7] Lightbown, P. M., \& Spada, N. (1999). How languages are learned. Oxford, UK: Oxford University Press.

[8] Biber, D., Nekrasova, T. \& Horn, B. (2011). The Effectiveness for L1-English and L2 Writing Development: A Meta Analysis. Educational testing services (ETS), 1110 .

[9] Ferris, D. (1999). The Case for Grammar Correction in L2 Writing Classes: A Response to Truscott (1996). Journal of second language writing, 8 (1), 1-11.

[10] Ferris, D. \& Robberts, B. (2001). Error Feedback in L2 Writing Classes. How Explicit Does It Need To Be? Journal of second language writing, 10, 161-184.

[11] Ferries, D., Liu, H., Sniha, A., and Senna, M. (2013). Written Corrective Feedback for Individual L2 Writers. Journal of second language writing, 22, 307-329.

[12] Truscott, J. (1996). The Case Against Grammar Correction in Second Language Writing Classes. Language learning, 46 (2), 327-369.

[13] Truscott, J. (2004). Evidence and conjecture on the effects of correction: A response to Chandler. Journal of second language writing, 13, 337-343.

[14] Truscott, J. (2007). The effect of error correction on learners' ability to write accurately. Journal of second language writing, 16, 255-272.

[15] Truscott, J. (2010). Further thoughts on Anthony Bruton's critique of the correction debate. System, 38, 626-633.

[16] Chandler, J. (2003). The efficacy of various kinds of error feedback for improvement in the accuracy and fluency of L2 students' writing. Journal of second language writing, 12, 267-296.

[17] Meihami, H. (2013). Truscott's claims in giving corrective feedback: Does it matter in EFL writing context? International letters of social and humanistic sciences, 8, 8-23.

[18] Williams, J. G. (2003). Providing Feedback on ESL Students' Written Assignment. The internet TESL journal, No. 10, http://iteslj.org/Techniques/Williams-Feedback.html

[19] Van Beuningen, C. G., De Jong, N. H., and Kuiken, F. (2011). Evedience on the effectiveness of comprehensive error correction in second language writing. Language learning, 62, $1-41$.

[20] Bitchener, J., \& Knoch, U. (2010). Rising the Linguistic Accuracy Level of Advanced L2 Writers with Written Corrective Feedback. Journal of second language writing, 19, 207-217.

[21] Farid, S., \& Samad, A. A. (2012). Effects of Different Kind of Direct Feedback on Students' Writing. Social and behavioral sciences, 66, 232-239.

[22] Kao, C. W. (2013). Effects of focused feedback on the acquisition of two English articles. Teaching English as a second or foreign language, 17.1, 1-15.

[23] Mourssi, A. (2012). The impact of reflection and metalinguistic feedback in SLA: A qualitative research in the context of post graduates. The international journal of language learning and applied linguistics world (IJLLALW), 1 (1), 128-146.
[24] Evans, N. W., Hartshorn, K. J., and Strong-Krause, D. (2011). The Efficacy of Dynamic Written Corrective Feedback for University-matriculated ESL Learners. System, 39, 229-239.

[25] Ding, T. (2012). The comparative effectiveness of recasts and prompts in second language classrooms. Journal of Cambridge Studies, 7 (2), 83-97.

[26] Jeong, L. (2012). Corrective feedback preferences and learner repair among advanced ESL students. System, 1-14.

[27] Sheen, Y. \& Ellis, R. 2011. Corrective feedback in language teaching. In: E. Hinkel, ed., Handbook of research in second language teaching and learning. Vol. 2. New York: Routledge, 593-610.

[28] Sato, M., \& Lyster, R. (2012). Peer Interaction and Corrective Feedback for Accuracy and Fluency Development. Studies in second language acquisition, 34 (04), 591-626.

[29] Ellis, R., Sheen, Y., Murakami, M. \& Takashima, H. 2008. The effects of focused and unfocused written corrective feedback in English as a foreign language context. System. 36, 353-371.

[30] Bitchener, J. (2008) Evidence of Support of Written Corrective Feedback. Journal of second language writing, 17, 102-118.

[31] Lam, R. (2013). Two Portfolio Systems: EFL Students' Perceptions of Writing Ability, Text Improvement, and Feedback. Assessing writing, 18, 132-153.

[32] Nazari, N. (2013). The Effect of Implicit and Explicit Grammar Instruction on Learners' Achievements in Receptive and Productive Modes. Social and behavioral sciences, 70, 156-162.

[33] Falhasiri, M., Tavakoli, M., Hasiri, F., \& Mohammadzadeh, A. R. (2011). The effectiveness of explicit and implicit corrective feedback on inter-lingual and intra-lingual errors: A case of error analysis of students' compositions. Canadian Center of Science and Education, English language teaching, 4 (3), 251264.

[34] Clerckx, B., Kim, G., Choi, J., \& Hong, Y.-J. (2010). Explicit vs. Implicit Feedback for SU and MU-MIMO. 2010 IEEE global telecommunications conference, GLOBECOM, 1-5.

[35] Campillo, P. S. (2003). An analysis of implicit and explicit feedback on grammatical accuracy. Journal of English and American studies, 27, 209-228.

[36] Marzban, A. \& Arabahmadi, S. (2013). The effects of written corrective-feedback on Iranian EFL students' writing. 2nd world conference on educational technology research. Social and behavioral sciences. 83, 1000-1005.

[37] Miceli, T. (2006). Foreign language students' perception of a reflective approach to text correction. Flinders University Languages Group Online Review, 3 (1), 25-36, Retrieved from http://ehlt.flinders.edu.au/deptlang/fulgor/

[38] Zhao, H. (2010). Investigating learners' use and understanding of peer and teacher feedback on writing: A comparative study in a Chinese English writing classroom. Assessing writing, 15 (1), 3-17.

[39] Yilmaz, Y. (2013). The relative effectiveness of mixed, explicit, and implicit feedback in the acquisition of English articles. System, 41, 691-705. 
[40] O'Neill, M. (2005). Automated use of a wiki for collaborative lecture notes. ACM SIGSCE Bulletin, 37, 267-271.

[41] Wagner, C. 2004. Wiki: A technology for conversational knowledge management and group collaboration. Communications of the Association for Information. System. $13,265-289$.

[42] Ebersbach, A., Glaser, M. \& Heigl, R. (2006). Wiki: Web collaboration. Berlin Heidelberg, Springer-Verlag.

[43] Ruth, A. \& Houghton, L. (2009). The wiki way of learning. Australian journal of education technology, 25, 135-152.

[44] Ben-zvi, D. (2007). Using Wiki to Promote Collaborative Learning in Statistics Education. Technology innovations in statistics education (TISE), Center for the Teaching of Statistics, UCLA. UC Los Angeles.

[45] Kovacic, A., Bubas, G., \& Zlatovic, M. (2007). Evaluation of Activities with a Wiki System in Teaching English as a second language. 2-5.

[46] Parker, R. P., \& Chao, J. T. (2007). Wiki as a teaching tool. Interdisciplinary Journal of Knowledge and Learning Objects. Retrieved September 2, 2010.

[47] Ren, Y., \& Gong, C. (2011). An Empirical Study on Application of Wiki-based Collaborative Lesson-Preparing. International conference of information technology computer engineering and management sciences, IEEE.

[48] Wang, H., Lu, C., Yang, J., Hu, H., Chiou, G., \& Hsu, W. (2005). An Empirical Exploration of Using Wiki in an English as a Second Language Course. Fifth IEEE international conference on advanced learning technologies (ICALT'05).
[49] Biasutti, M. and EL-Deghaidy, H. (2012). Using wiki in teacher education: Impact on knowledge management process and students' satisfaction. Computers and education, 59, 861872 .

[50] Barry, S. (2012). A video recording and viewing protocol for student group presentations: Assisting self-assessment through a Wiki environment. Computers and education, 59 (3), 855860 .

[51] Umar, I., N., \& Rathakrishnan, M. (2012). The Effects of Online Teachers' Social Role and Learning Style on Students' Essay Writing Performance and Critical Thinking in a Wiki Environment. Social and behavioral sciences, 46, 5730-5735.

[52] Ng, E. (2014). Using a mix research method to evaluate the effectiveness of formative assessment in supporting student teachers' wiki authoring. Computers and education, 73, 141148.

[53] Macky, A. \& Gass, M. S. (2005). Second language research: Methodology and design. Mahwah, New Jersey, USA, Lawrence Erlbaum Associates, Inc.

[54] Wolfe-Quintero, K., Inagaki, S., \& Kim, H. Y. (1998). Second language development in writing: Measures of fluency, accuracy and complexity. University of Hawaii Press.

[55] Mackey, A. \& Goo, J. (2007). Interaction research in SLA: A meta-analysis and research synthesis. In A. Mackey (Ed.), 407-452.

[56] Farrokhi, F \& Mahmoudi, A. 2012. Rethinking Convenience Sampling: Defining quality criteria. Theory and practice in language studies. 2, 784-792. 